\title{
Indústria Cultural: líder glamourizado que sujeita indivíduos à condição de
} massa

Industria Cultural: líder glamouroso sometendo los individuos a la condición de masa Cultural Industry: glamorous leader subjugating individuals to a mass condition

\section{Regina Perez Christoffolli Abeche}

Universidade Estadual de Maringá, Maringá, PR, Brasil.

\author{
Rodrigo Daniel Trevizan
}

Universidade Estadual de Maringá, Maringá, PR, Brasil.

\section{Anne Caroline Alves Peres}

Universidade Estadual de Maringá, Maringá, PR, Brasil.

\section{Resumo}

Este trabalho objetiva relacionar o conceito de indústria cultural, cunhado por Theodor Adorno, e a sua relação com o líder/tirano anunciado no texto Psicologia das Massas e Análise do Eu, de Sigmund Freud, contextualizando-os na sociedade econômica atual. Para essa análise, foram contempladas as características do sistema neoliberal, a organização familiar atual, sendo que esta é uma das principais instituições intermediárias entre os indivíduos e o seu meio cultural. Esta análise permitiu identificar um desamparo dos indivíduos nesta atual sociedade devido ao consumismo e a concomitante valorização da Mercado(ria) em detrimento do humano.

Palavras-chave: Indústria Cultural, Massa, Neoliberalismo.

\section{Resumen}

Este trabajo pretende relacionar el concepto de industria cultural, acuñada por Theodor Adorno y su relación con el líder / tirano anunciado en el texto Psicología de las masas y análisis del Yo, de Sigmund Freud, contextualizandolos a la sociedad económica actual. Para este análisis, nos dirigimos a las características del sistema neoliberal, la organización de la familia actual, siento esta una de las principales instituciones de intermediación entre las personas y su entorno cultural. El 
análisis nos ha permitido identificar una impotencia de los individuos en esta sociedad actual a través de los valores del consumismo y la valoración de los bienes a expensas de lo humano. Palabras clave: Industria Cultural, Masa, Neoliberalismo.

\begin{abstract}
This study aims to relate the concept of cultural industry, developed by Theodor Adorno, and its relationship with the leader / tyrant announced in the text Psychology of Mass and Ego Analysis, by Sigmund Freud, contextualizing them in the current economic society. For this analysis, we highlighted the features of the neoliberal system, the current family organization, being that one of the main intermediary institutions between individuals and their cultural environment. The analysis identified a helplessness of individuals in this current society through the values of consumerism and the valuation of the goods rather than the human.
\end{abstract}

Keywords: Cultural Industry, Mass, Neoliberalism.

\title{
Introdução
}

Este trabalho objetiva entender os ditames da indústria cultural, conceito cunhado por Adorno, e a sua relação com o líder/tirano anunciado no texto Psicologia das Massas e Análise do $\mathrm{Eu}$, de Freud, relacionando-os com o consequente desamparo vivido pelos indivíduos submetidos, na sociedade contemporânea, aos valores disseminados e orquestrados pelo sistema econômico neoliberal via indústria cultural. Para esta análise, serão contempladas as características do sistema econômico vigente e a família atual, sendo esta última entendida como uma das principais instituições intermediárias entre os indivíduos e o seu meio cultural. A fundamentação teórica pauta-se na Teoria Psicanalítica - basicamente em Freud, no conceito de Indústria Cultural de Theodor Adorno, um dos representantes da Teoria Crítica da Escola de Frankfurt e em outros autores que investigam a temática proposta.

Os pilares metodológicos que sustentam este trabalho são: a pesquisa bibliográfica e a pesquisa qualitativa (Gonzalez Rey, 2005). A pesquisa qualitativa apoia-se no caráter construtivointerpretativo do conhecimento, cujo pesquisador ocupa uma condição ativa na produção do conhecimento. Utiliza-se também o método dialético-histórico, que parte da compreensão de que a realidade se entrelaça em vários aspectos e em diferentes níveis. Desta forma, os fatos são compreendidos no contexto histórico e não são compreendidos isoladamente. 
A seguir, serão descritas as características do sistema econômico neoliberal, alguns dos valores disseminados para a sua implementação e manutenção; o conceito de Indústria Cultural atualizado, sua relação com o líder tirano descrito por Freud no texto Psicologia das Massas e Análise do Eu, e por fim suas implicações nos indivíduos e nas famílias imersos nessa sociedade de consumo, que captura o desejo singular do indivíduo ao implantar o desejo compulsivo pelo consumismo, tanto de si quanto do outro, quanto dos objetos, desejo tão contemporâneo.

\section{Características do sistema econômico neoliberal}

Concomitantemente à consolidação do modo de produção capitalista, houve mudanças qualitativas nos valores culturais da sociedade, que repercutiram em mudanças qualitativas na subjetividade. $\mathrm{O}$ pensamento liberal iniciou-se com o advento do Capitalismo e desenvolveu-se fundamentando-se no ideal da Revolução Francesa, no século XVIII. Os ideais dessa revolução consistiam em um grande movimento de ideias nos âmbitos econômico, ético e político a fim de se contrapor ao anterior mercantilismo do Estado absolutista ${ }^{1}$ (Abeche, 2003).
Os pilares do pensamento liberal são a liberdade e a propriedade. Liberdade para o indivíduo ser dono da propriedade privada e dos meios de produção e/ou para vender sua força de trabalho; e, ainda, no que concerne ao mundo do trabalho, o indivíduo teria total responsabilidade sobre seus atos e suas consequências. Logo, nesse sistema, há um superinvestimento no indivíduo e este passa a ser o único responsável tanto pelo seu sucesso quanto pelo seu fracasso.

Sob a égide do liberalismo, "o capitalismo, no final da década de 20 do século XX, entra em crise dada à necessidade desenfreada de lucro e a falta de mecanismos reguladores" (Abeche, p. 43). Nesse contexto, surge a proposta da intervenção do Estado de bem-estar social, que entra em vigor para garantir ações públicas de qualidade, tais como saúde, educação e outras (idem). Na década de 1970, o Estado de bem-estar social foi duramente criticado ao ser visto como prejudicial ao crescimento econômico mundial. Abriu-se, assim, um caminho à elaboração de um novo liberalismo, ou seja, o neoliberalismo. As configurações desse novo sistema provocaram a diminuição do Estado de bem-estar social e fizeram com que o indivíduo - e somente ele - fosse o responsável pela provisão de elementos como saúde e educação, que estavam sob responsabilidade estatal. 
Assim, além do indivíduo ser o único responsável pelo seu sucesso, também é culpabilizado pelos seus fracassos. $\mathrm{O}$ neoliberalismo exacerbou o individualismo já existente: “[...] no mundo dos indivíduos há apenas outros indivíduos", confirmando a idéia de "cada um por si e Deus por todos" (Abeche, 2003, p. 43).

Com a implantação do neoliberalismo, conforme Carrobles (2003), ocorreram também importantes mudanças na instituição família, pois com a fragilização dos laços de dependência econômica, as famílias agora têm de se ocupar com compromissos adicionais sem a ajuda do Estado.

Ainda no dizer de Abeche (2003), "o neoliberalismo concilia o individualismo com as exigências da vida social, apresentando o mercado como aquele que resolve tudo" (p. 45), e como consequência, "o indivíduo reina soberano, mas solitário". Nessa linha de raciocínio, Enriquez (2006) afirma que nesse sistema “O homem tem, cada vez mais, a solidão como companheira" (p. 6).

O homem do neoliberalismo troca os vínculos sociais por uma liberdade ideológica, que o faz pensar ser autônomo. Nesse novo contexto, os indivíduos desconsideram o impacto do sistema político-econômico vigente no processo histórico, nas diferenças de classes, na pobreza e no desemprego progressivo, e aceitam a condição de serem os únicos responsáveis /culpados; no entanto o grande orquestrador dessa nova condição encontra-se no próprio sistema.

A razão prevalente, nesse contexto neoliberal, consiste na razão instrumental, que teve sua origem com 0 desenvolvimento do Iluminismo. A razão instrumental, em consonância com Fabiano (2001), seria a exaltação e uso da racionalidade com a pretensão de acabar com os mitos e com a irracionalidade frente à natureza, para atingir um desenvolvimento científico e tecnológico a fim de melhor atender aos interesses econômicos da classe dominante. No entanto, a racionalidade, que deveria proporcionar a emancipação dos homens, por meio da autonomia, transformou-se em um engodo. Engodo ocasionado por duas razões: ao servir a uma ciência instrumental, a própria razão se tornou mito, e para atender de forma exclusiva aos interesses da classe dominante dita esclarecida - burguesia -, que estava à frente da revolução e que se manteve no poder (Adorno, 1971/2006).

A razão instrumental/técnica funciona para manter o indivíduo na reprodução e fortalecimento do capitalismo (Adorno, 1995). Portanto, a razão, nesse contexto, não era utilizada para pensar os interesses ocultos de quem propunha a razão técnica como instrumento de 
produção e reprodução de ideologias. Com a prevalência da técnica, a razão perdeu, desde o Iluminismo, seu caráter de superação para se transformar em um mito encobridor da verdade e do próprio processo histórico. O homem, alienado pela razão instrumental e suas ideologias, reproduz o status quo como algo natural, inevitável.

De acordo com Enriquez (2006), a racionalidade instrumental responde à pergunta como?, e não à pergunta por $q u \hat{e}$ ?, "O que corresponde à manutenção e favorecimento apenas da racionalidade econômica, aquela que permite o cálculo dos melhores métodos, o cálculo de custos e de vantagens, a fim de submeter todos ao reino do dinheiro" (Enriquez, 2006, p. 4) e não à uma razão crítica que estaria a serviço do desenvolvimento humano. Assim, "a classe dominadora, através da ideologia neoliberal, utilizando-se da racionalidade instrumental e das estratégias financeiras, alcança seu objetivo: utilizar o sujeito, que acredita ser em grande parte autônomo, para superexplorá-lo e alienálo" (Enriquez, 2006, p. 6).

A sociedade atual valoriza o dinheiro, o lucro, em detrimento do humano, pensamento este representado na ideia difundida: "tudo se compra e tudo se vende" (Enriquez, 2006). Ainda segundo este autor, no mundo globalizado, vive-se em uma guerra que se intensifica a cada dia, responsável por aumentar as diferenças de classes e até de países, que resulta, frequentemente, em benefício dos mais ricos; portanto, assiste-se a um aumento contínuo das desigualdades. Em outras palavras: na globalização, as trocas também beneficiam essencialmente os países ricos - que sabem como se proteger quando lhes parece necessário. Nas palavras de Enriquez, "o mundo atual tende a tornar-se o do crescimento do desprezo, da generalização da desconsideração, do desrespeito, da recusa da diferença a que tem direito todo ser humano" (2006, p. 6).

Para Adorno, "a racionalidade técnica hoje é a racionalidade da própria dominação. Ela é o caráter compulsivo da sociedade alienada de si mesma" (1947/2006). A técnica gerou a padronização e a produção em série; logo, é esclarecedor pensar o papel que a razão técnica ainda exerce no sistema econômico atual. O conceito de Adorno (1978) de Indústria Cultural elucida o poder dos dominantes por meio dessa racionalidade técnica.

\section{Conceito de Indústria cultural atualizado}

Adorno (1978) postula o conceito de indústria cultural para substituir o conceito de cultura de massa, pois parte da 
compreensão de que os indivíduos vivem em uma cultura que não surge direta e espontaneamente das massas, mas é produzida pela classe hegemônica e imposta à sociedade, sob a forma de ideologia, para estimular o consumo, propiciando "falsas experiências sociais".

Nessa linha de raciocínio, Abeche (2003) enuncia que para a manutenção da hegemonia do sistema neoliberal é fundamental manipular/formar mentalidades que se moldem às necessidades do mercado, manejo realizado, principalmente, via mídia, submetida aos ditames do sistema político econômico atual. A estratégia pela qual a mídia logra difundir valores de consumismo da Indústria Cultural é a sedução. Essa palavra, segundo Lucchesi (2002), provém do latim seducere (se[d] + ducere).Sed, além de conjunção equivalente a "mas", atuava nos textos antigos como prevérbio, significando "separação", "afastamento", "privação"; e ducere queria dizer "levar", "guiar", "atrair". Em síntese, portanto, "seduzir" nos remete ao processo pelo qual se atrai para privar o outro da autonomia de si, sob a promessa de possibilitar-lhe a experiência do prazer pleno.

Em consonância com Adorno (1947/2006), o sistema de comunicação de massas não se constitui como um veículo da arte, mas como um negócio que se destina a "legitimar o lixo que propositalmente produzem" (p. 57). Os sistemas, responsáveis por difundir certa cultura, encontram-se dependentes de indústrias poderosas economicamente e, por conseguinte, os setores supostamente particulares estão totalmente dependentes da rede econômica. Adorno assinala que nessa rede está tudo tão "justaposto" que forma uma unidade implacável, pois "para todos algo está previsto, para que ninguém escape, as distinções são acentuadas e difundidas" (p. 58).

Nesse cenário, os produtos são diferenciados na aparência para manter a ilusão de escolha do consumidor, porque cada um deve escolher "a categoria dos produtos de massa fabricada para o seu tipo", que no final revelam ser sempre a mesma coisa, apesar das (sempre velhas) novas roupagens (Adorno, 1947; 2006; p. 58). Desta forma, o produto chega ao consumidor pronto e acabado e nada precisa ser pensado ou transformado. A arte, enquanto potência criativa de expressão e reflexão da realidade, encontra-se capturada pela mediocridade, visível nos velhos/novos espetáculos, que muda ao transmutar-se apenas na aparência, porque o seu conteúdo mantémse invariável, constatada nos antigos clichês caiados, apresentados e ansiosamente esperados pelo 
espectador/consumidor (Adorno, 1947; 2006).

Podemos assinalar que: a indústria cultural significa a irracionalidade de uma sociedade demasiadamente racional. A mercadoria apresenta-se como um prolongamento da vida cotidiana para que o indivíduo assista, identifique-se, mas não reflita. A violência da sociedade industrial instalou-se nos homens, pois até os mais desinteressados/distraídos transformam-se em consumidores da indústria cultural. Esta última se alastrou e se organizou de tal forma que tanto o trabalho quanto o lazer foram cooptados para a sua produção e reprodução. Por fim, nas palavras de Adorno, a indústria cultural reproduz pessoas para atender a "gigantesca maquinaria econômica" (1947/2006, p. $60)$.

Assim, a indústria cultural difunde um modo de vida predeterminado, e um dos meios de maior propagação encontrase no lazer, apresentando-se como "indústria da diversão". Nesse atual contexto atual divertido, "o Mercado mantém os indivíduos aprisionados livremente ao produto, ao sucumbirem sem nenhuma resistência ao que lhes é oferecido" (Adorno,1947; 2006, p. 63), e ainda "A verdade em tudo isso é que o poder da indústria cultural provém de sua identificação com a necessidade produzida [...]" (Adorno, 2006, p. 64). E as necessidades são produzidas e saciadas pela própria indústria cultural.

Há, na atualidade, uma dessimbolização do mundo (Dufour, 2003) causada pelo neoliberalismo, quando este transforma todas as formas de troca da aldeia global, reduzindo-as a um denominador comum: o valor monetário. $\mathrm{O}$ neoliberalismo colaborou para um empobrecimento do mundo simbólico, visto que o símbolo constitui a forma do sujeito, por excelência, pensar e interagir no mundo. $\mathrm{O}$ sujeito de hoje, submetido às estratégias do mercado/capital, encontra-se impossibilitado/impedido de pensar de modo crítico a sua realidade (Adorno, 1947; 2006) por lhe ser dificultado o desenvolvimento de suas capacidades superiores - como o raciocínio, atenção, memória, abstração e análise - o que o mantém no predomínio do pensamento do tipo fantasioso e acrítico. Sem capacidade plena de discernir, o indivíduo torna-se uma presa fácil, facilitando a sua manipulação.

Assim, anuncia Dufour (2003, p. 2):

o valor simbólico desmantelado em
proveito do valor monetário da mercadoria
impossibilita que qualquer consideração,
moral, tradicional, transcendente,
transcendental..., obstacularize a
concepção de que o valor monetário


constitui o intermediário para todas as relações de troca.

Para Adorno (1947; 2006), a indústria cultural objetiva eliminar todo pensamento que possa se tornar uma resistência ao sistema vigente, e para isso, ela reduziu tudo à repetição e logra os consumidores com promessas de satisfação que ficam apenas nas promissórias, portanto "apresenta a satisfação como uma promessa rompida" (p. 66 - grifos nossos), fatos que mantêm $\mathrm{o}$ seu poder $\mathrm{e}$ corroboram com a "vitória da razão tecnológica sobre a verdade".

A indústria cultural atende à necessidade do sistema de manter em clausura o consumidor. Enclausurando-o, dificulta ao indivíduo, já consumido e consumidor, visualizar e pressentir a possibilidade da resistência. A indústria cultural preconiza que todas as necessidades do indivíduo podem ser satisfeitas a partir dela, mas essas necessidades devem ser organizadas de tal monta que o indivíduo se veja unicamente como um eterno adepto do consumismo, enfim, o indivíduo como objeto reificado/coisificado, em busca de objetos glamourizados (Adorno, 1947; 2006, p. 67).

Neste momento histórico, sob a égide da indústria cultural, tudo é descartável, como produto utilizado, que não cumpriu a promessa de saciar seu consumidor. Essa lógica da descartabilidade, entretanto, não limita-se somente à relação sujeito-mercadoria, mas também é regente das relações entre os próprios sujeitos, pois estes também são vistos como mercadoria a ser consumida na lógica do "ficar com" (Abeche \& Ferreira Junior, 2010). Ao incorporar a lógica de mercado no relacionamento afetivo-sexual, como apresentado no "ficar com", enquanto código de relacionamento, notamos a manifestação de uma lógica reificada em harmonia com os parâmetros da sociedade neoliberal: com base na lógica do descarte e da troca, em que o não-novo e o estático são desvalorizados socialmente. $\mathrm{O}$ indivíduo, assim, acaba por cair em um engodo que lhe dificulta a possibilidade de ter experiências formativas. A indústria cultural, enfim, se mantém na captura de tudo e de todos para confirmar o poder hegemônico da burguesia pela sua ideologia.

\section{A ditadura do tirano da atual antiga} indústria cultural na teoria freudiana e suas implicações nas famílias e nos indivíduos imersos nesta sociedade de consumir(-se)

Freud, em seu famoso texto MalEstar na Cultura (1930), no início do século passado, afirmou que o homem, em 
seu estado natural e não-civilizado, possuía originalmente pulsões agressivas e sexuais que, se não contidas, impossibilitariam a convivência social. O ser humano, a fim de fazer parte de uma cultura e desfrutar dos seus benefícios, renunciaria à satisfação imediata de tais pulsões, para, em troca, obter o conforto e a segurança, isto é, o amparo tão necessário à sobrevivência e à vida.

Contudo, diante desta sociedade organizada e permeada por valores que priorizam a razão técnica, a competição e a manutenção do status quo em detrimento do humano, da arte e das relações, surge uma pergunta: a sociedade de fato está servindo como amparo ao humano?

Freud (1921/2005) registra que na vida psíquica individual está sempre presente um outro, que serve de modelo, objeto, auxiliar ou adversário. Desse modo, não é possível compreender o indivíduo fora de uma perspectiva coletiva. No dizer de Freud, "la psicología colectiva considera al individuo como miembro de una tribu, de un pueblo, de una casta, de una clase social o de una instituición [p. 8]". Remete também à importância da formação do instinto social do indivíduo a partir da relação com sua família ao registrar que "el instinto social no es um instinto primário e irreducible, y que los comiezos de su formación pueden ser allados em círculos más limitados; por ejemplo, el de la família” (p.8).

Ao entender que o instinto social começa a ser formado na família, e sendo a família uma representante, principalmente, dos valores do contexto macrossocial, resta questionar: que possibilidades de formação e desenvolvimento humano estão sendo oferecidas aos indivíduos nesta sociedade de consumo construída e mantida via indústria cultural?

A família é considerada a matiz do desenvolvimento psíquico, na qual cada indivíduo desenvolve a sua identidade, consciente e inconsciente, e também pelas identificações com os valores e regras de sua família. Logo, a família constitui um sistema de elementos em interação que é paradigmática e base para a estrutura social maior - cultura - como uma das muitas instituições que mantém esta última.

Para Groeninga (2003), a família faz parte de um sistema em que a interação transcende as somas das partes, ou seja, é uma relação em que todos os membros interagem em uma interdependência e interagem também com a sociedade na qual estão inseridos, modificando-se com o tempo. A família nem sempre apresentou a mesma estrutura e dinâmica. Groeninga (2003) pondera que a família é um “caleidoscópio de relações que muda no tempo de sua constituição e consolidação em cada geração, que se transforma com a 
evolução da cultura, de geração para geração" (p. 125), mas ao mesmo tempo considera a família a "célula máter" da sociedade como uma instituição que provoca os mais caros sentimentos.

Os vínculos afetivos encontram-se fragilizados na sociedade pós-moderna, inclusive no âmbito familiar, porque esses passam também a ser regidos pela lógica mercadológica. Segundo Carrobles (2003), “as famílias decrescem de tamanho e tornam-se cada vez mais instáveis, diminui a valorização da família em razão da valorização do individualismo" (p. 26 grifos nossos).

De acordo com Kehl (2003), com a dita liberdade de escolha apregoada pela indústria cultural, tornou-se possível corrigir o futuro "sem-número de vezes", o que pode acarretar uma insegurança que posteriormente se traduz em desamparo e mal-estar. O desamparo provém da família, que deixa de ser uma sólida instituição para ser engolfada pela lógica da coisificação do humano, que acabou por se transformar em um "agrupamento circunstancial e precário regido pela lei menos confiável entre os humanos: a lei dos afetos e dos impulsos sexuais" (p. 165). Já os novos mal-estares provêm da dívida para com a família nuclear, oferecidos pelos pais/avós, ao compará-la à que se tornou possível, nesta contemporânea cultura do consumismo (Kehl, 2003).

Segundo Kehl (2003), três grandes transformações recentes influenciaram a instituição família: a entrada das mulheres no mundo do trabalho, que ao ficarem com parte dos salários destinados aos homens emanciparam-se financeiramente; uma "explosão" dos meios de comunicação de massa que disseminou novos valores e padrões de comportamento até nas famílias mais conservadoras, e que enfraqueceu a forma de transmissão de valores, outrora feita quase unicamente pela família; e a última, e a mais decisiva, a democratização dos métodos contraceptivos, que modificou a relação e o planejamento familiar. A mulher passou a valorizar a satisfação sexual na escolha de seu cônjuge. Destarte, “[...] os filhos deixaram de ser a finalidade, ou consequência inevitável, dos encontros eróticos" (Kehl, 2003, p. 169).

Paralelamente à confusa árvore hiper-ramificada descrita por Kehl (2003), que se caracteriza pelas famílias refeitas formando as famílias tentaculares, há a invasão no convívio familiar pelos meios de comunicação, como televisão e internet, que, onipresentes, modificaram a dinâmica familiar. Este novo contexto exige uma maior resistência dos pais para se contrapor ao imposto pela indústria cultural, pois não dispõem da ordem, dos valores e tradições a que estavam 
submetidos anteriormente, sendo necessário, assim, revestirem-se de uma nova autoridade para transmitir valores, orientar e cuidar dos filhos.

No império do consumo, não são benquistos os vínculos duradouros, pois sem o descarte não há a possibilidade de se implantar o desejo de novos objetos e não há como seduzir com novas promessas de felicidades. Sobre isso, Abeche \& Rodrigues (2005) asseveram que "na contemporaneidade, a estrutura familiar se encontra extremamente fragilizada, em que casamentos se dissolvem, não só devido à incompatibilidade de idéias, identidades e aspirações, mas a cobranças externas derivadas do estilo de vida vigente” (p. 26 - grifos nossos).

Salazar (2002) anuncia que houve, nos anos 1960 e 1970, o surgimento da ética da contracultura, na qual "A utopia da boa alma já não é mais valorizada e os valores de amor à pátria e família são substituídos pelo discurso de liberdade individual" (Idem, id. - grifos nossos). Acrescenta, ainda, que a liberdade a partir da década de 80 encontra-se intensificada pelo neoliberalismo, que é a razão dessa nova ética em voga, a ética da felicidade. "Nesta sociedade pós-moralista a felicidade substitui o mandamento moral, o prazer substitui a proibição, a sedução substitui a obrigação, o desejo substitui o dever” (p. 2). Lipovetsky (1994 citado por
Salazar, 2002, p. 2) apregoa que "na época da felicidade narcísica 'tudo é permitido', 'moral sem obrigação e sem sanção"”.

Nessa nova ética, há um esvaziamento dos valores morais em benefício do indivíduo que se diz livre por direito. Como aponta Salazar (2002), a família deixa de ser tão somente uma instituição transmissora dos deveres para se transformar em uma instituição a serviço da realização pessoal.

Freud, em "O mal-estar na civilização" (1930/2006), informa que a mulher (já) apresentava conflitos com a civilização, pelo fato do homem se destinado ao trabalho, este precisava efetuar "uma distribuição conveniente de sua libido" extraída da mulher e da vida sexual, ou seja, da família. Na atualidade, com a entrada da mulher no mercado de trabalho, ela também necessita fazer uma nova distribuição de sua libido, e a família novamente perde uma parcela desse investimento.

Com os imperativos modernos da ética da felicidade uma parcela maior de libido está dirigida à busca da realização/sucesso pessoal. Uma das insígnias da felicidade na atualidade encontra-se no consumo, e assim o indivíduo, ao buscar felicidade, encontra o apoio necessário nesta sociedade consumista, que incita o consumo como o melhor estilo de vida. 
O trabalho, hoje, propiciador do consumismo, tem primazia, tanto para o homem quanto para a mulher, em detrimento dos relacionamentos afetivos. A construção de laços afetivos ficou relegada pelo investimento no trabalho. Cônjuges/pais e mães não possuem tempo real/cronológico e nem mental para dedicarem a si, ao cônjuge e nem aos filhos, e estes ficam à mercê dos "ensinamentos" da indústria cultural, que dissemina os imperativos atuais de consumo e acaba por formar mentalidades para a manutenção do status quo.

A instituição familiar, mesmo imersa neste turbilhão, permanece com a sua função formadora, ainda que de forma diferente. Como assegura Groeninga (2003), dada a dependência e o desamparo constituinte da natureza humana, a função da família, embora sofra variações históricas, mantém-se essencialmente como instituição estruturante do indivíduo. Se a família se apresenta nessa função, indagamos: como essas mudanças estruturais na família estão atingindo a formação dos indivíduos?

A indústria cultural consegue, através da sugestão (Freud, 1921/2005), enfraquecer a personalidade consciente e inconsciente, a vontade e o desejo. Os indivíduos ficam à mercê de um líder/que detém o poder e uma ideologia, que comanda por meio da indústria cultural, utilizando-se dos processos que atingem o funcionamento inconsciente dos indivíduos, de modo a produzir e a mantêlos no conformismo do sistema como sujeito não-pensantes, mas consumidores.

Os indivíduos, desta maneira, formam uma massa comandada por um líder tirânico - o capital. A indústria cultural mantém os indivíduos ligados uns aos outros na forma de uma multidão/massa de sujeitos não-pensantes, contagiados pelas mesmas emoções, como afirma Freud (1921/2005), “entonces el individuo llega a ser incapaz de mantener uma actitud crítica y se deja invadir por la misma emoción" (p. 22). Assim forma uma massa simbiótica, pois "su afectividad queda extradionariamente intensificada $\mathrm{y}$, en cambio, notablemente limitada su actividad intelectual” (idem, p. 25).

Como exposto, no sistema econômico vigente, os indivíduos formam uma grande massa manipulada (pela indústria cultural) para que os dominantes mantenham-se no poder. Nesse sentido, constatamos o predomínio do desamparo, pela carência de referenciais afetivos que também ofereceriam - caso não estarem impregnados pelo sistema -, elementos de realidade para contribuir na construção de uma razão crítica/analítica. Também observamos a prevalência, onipotente e onipresente, da indústria cultural, que dissemina modelos identificatórios a fim 
de manter o consumo em alta. Como demonstra Dufour (2001):

A falta de um enunciador coletivo confiável caracteriza a situação do sujeito pós-moderno, que sente ser-lhe imposto o "fazer por si mesmo" sem que possua os meios para tal, sem que haja uma antecedência histórica ou geracional que o oriente, e nem por isso seja legitimado a fazê-lo (p.1).

Em outras palavras, o homem se confronta neste momento histórico com a necessidade de ser autorreferencial. Sobre isso, Tenzer (1991) argumenta:

Pela primeira vez o indivíduo encontra-se frente a uma sociedade, sem chaves para compreendê-la e construir seu futuro, obrigado a aceitar um sistema político que se lhe impõe no seu interior, forçado a construir sozinhas suas próprias regras de conduta, confrontando-se com um risco maior de solidão (p. 175).

Portanto, conseguinte às características desta sociedade pósmoderna (marcada pelo e para o consumo e a competição), encontra-se uma estreita relação com uma intensa vivência de desamparo. $\mathrm{Na}$ contemporaneidade, para Caniato, Martins e Teixeira (2008), a indústria cultural oferece diversos modelos identificatórios facilmente descartáveis, flutuantes, que carregam em seu bojo uma valorização do imediatismo e da ideia de autossuficiência. Ainda nas palavras de Martins (2009), com as transformações do mundo globalizado "há o excesso de regulamentação que desregulariza e desprotege o sujeito empurrando-o para o desamparo" (p. 111).

Nesta atual sociedade de consumo, os indivíduos tornam-se menos capazes de renunciar ao prazer imediato e apresentam dificuldades em tolerar a frustração. Klein (1963/1991) aponta que a renúncia

[...] permite ter prazer com aquilo que está
disponível sem muita voracidade por
gratificações inacessíveis e sem
ressentimento excessivo diante da
frustração. A renúncia está ligada à
tolerância e ao sentimento de que os
impulsos destrutivos não sobrepujarão o
amor e que, portanto, as coisas boas e a
vida podem ser preservadas (p. 351).

Devido a essa dificuldade em renunciar, os vínculos afetivos fragilizamse, e o sentimento de desamparo torna-se mais presente. Martins (2009) assinala que amparo significa ter apoio e ajuda do outro ou algo, e exemplifica como fonte de amparo a família, a religião, a sociedade e o Estado. Portanto, o amparo depende de outro indivíduo ou instituição que o propicie, pois sozinho o indivíduo não o encontrará. O objeto que serve de amparo encontra-se no outro, externo a si, assim o 
homem não pode prescindir do outro para ser feliz (Martins, 2009). Isto pode ser observado, de modo inequívoco, na expectativa/necessidade da presença de outrem para a sobrevivência do bebê, e também na frustração inevitável e esporádica colocada pelo outro que o faz amadurecer. O outro serve ao bebê como uma imagem idealizada, como um referencial para internalizar, com a tarefa de colaborar no desenvolvimento das capacidades superiores do psiquismo. No entanto, nesta cultura em que o outro humano se encontra tão desvalorizado, presenciamos um empobrecimento do mundo interior.

Os indivíduos, sem apoio e alienados, comandados por um líder tirânico, representado na contemporaneidade pela indústria cultural, formam uma massa, constituída por um grupo simbiótico altamente sugestionável, com afetos exacerbados e com intelecto defasado (Freud, 1921; 2005):

O sistema atual só se interessa por clientes e empregados e, para isto reduziu a humanidade, a essas duas fórmulas exaustivas.[...] Enquanto empregados, eles são lembrados da organização racional e exortados a se inserir nela com bom-senso. E enquanto clientes, verão cinema e a imprensa [mídia] demonstrarem-lhes, com base em acontecimentos da vida privada das pessoas, a liberdade de escolha, que é canto e o encanto do incompreendido. Por fim, o homem encontra-se na condição de coisa/objeto em ambos os casos (Adorno, 1947; 2006, p.69).

Freud (1921/2005) em seu livro 'Psicologia de massa e Análise do Eu', oferece subsídios para entendermos a organização psíquica do indivíduo na atualidade, submetido a uma ideologia, por meio da indústria cultural, ao descrever o comportamento do indivíduo em uma situação de massa. Para Freud (1921; 2005), a massa constitui um grupo de indivíduos que se encontram em um estado de indiferenciação entre seus componentes, na qual as características individuais são suprimidas e a massa comporta-se como se fosse um único indivíduo. $\mathrm{O}$ que rege os comportamentos homogêneos e heterônomos destes são os interesses de um líder, seja este uma pessoa real, ou um substituto, como um objetivo em comum, uma instituição ou uma ideia. $\mathrm{O}$ autor cita dois exemplos de massa: o exército e a igreja. Em tais casos, os indivíduos seguem um modo de comportar-se uniformizado, a partir de um líder em comum. No primeiro, o líder (representado por um general) segue a ideia de patriotismo, enquanto na igreja o líder preconiza os ideais cristãos.

$\mathrm{Na}$ condição de massa, os indivíduos funcionam pelo processo primário do psiquismo. Para Laplanche e 
Pontalis (1996), este é o funcionamento do sistema inconsciente, em que a energia psíquica flui livremente e tende a reproduzir as experiências primitivas de satisfação do indivíduo. Esse funcionamento é regido pelo princípio do prazer, no qual o indivíduo vê-se incapacitado de postergar uma satisfação dada a impossibilidade de conceber a realidade externa. Nesse modo de funcionamento, as capacidades superiores, como atenção, raciocínio, discernimento e julgamento crítico, não são plenamente utilizados. LeBon (1855, citado por Freud, 1921; 2005) deixa claro que para os indivíduos que se encontram em uma massa (como são os expectadores da indústria cultural), se lhes é conferida uma espécie de alma coletiva, e

Esta alma les hace sentir, pensar y obrar de una manera por completo distinta de cómo sentiría, pensaría y obraría cada uno e ellos aisladamente. Ciertas ideas y ciertos sentimientos no surgen ni se transforman en actos, sino en los individuos constituidos en multitud. (p. 10)

Destarte, um indivíduo inserido em uma massa encontra-se altamente sugestionável, regido pelo processo primário, perde seu senso de responsabilidade, e por fim, encontra-se transformado em um autômato (Freud, 1921; 2005). Podemos entender que, tendo em vista o conceito de indústria cultural, a grande ideia que lidera os indivíduos na contemporaneidade, enquanto massa acrítica, já não é mais o patriotismo ou uma religião, mas sim a lógica do consumismo. A indústria cultural faz com que os indivíduos, com sua singularidade suprimida, submetam-se ao grande interesse do líder (capital) disseminado principalmente via midiática: "consumo, logo existo".

\section{Considerações... O que buscamos e podemos perceber}

Ao partir da relação indivíduocultura, o cenário que rege a vida dos indivíduos contém a presença onipresente da Indústria Cultural como um líder tirânico que, por meio do engano e da sedução (privação do indivíduo da autonomia de si), principalmente via peripécias da mídia que se apresenta como divertimento, mantém o sujeito funcionando como um ser não-pensante, regido predominantemente sob o processo primário de pensamento (Freud, 1921; 2005; Adorno, 1947; 2006). Esse funcionamento leva o sujeito para a formação de massa, simbiótica, com os outros e a um estado de desamparo. As instituições que serviriam para amparar o indivíduo nas suas necessidades, particularmente a família e o Estado, se 
enfraquecem diante do poder hegemônico da indústria cultural, cujo "amparo" oferecido não se traduz no atendimento das necessidades eminentemente humanas e no desenvolvimento social, mas sim na manutenção de um sistema cuja principal finalidade é a automanutenção e a satisfação desenfreada dos interesses de uma minoria economicamente privilegiada.

Enfim, este trabalho foi realizado para expandir a compreensão e também abrir caminhos para que novas reflexões e avanços teóricos sejam suscitados acerca dessa temática que se faz tão presente na contemporaneidade.

\section{Notas}

1 O mercantilismo do Estado absolutista canalizava as atividades produtivas unicamente ao desenvolvimento e fortalecimento do Estado, cerceando a livre iniciativa no âmbito da economia (Abeche, 2003).

\section{Referências}

Abeche, R. P. C. Uma análise do impacto dos meios de comunicação. (2003) Em: Abeche, R. P. C. Por trás das câmeras ocultas a subjetividade desvanece. Tese de doutorado. Universidade Metodista de São Paulo: São Bernardo do Campo.
Abeche, R. P. C.; Rodrigues, A. A. (2005) Família contemporânea, uma instituição em questionamento: transição ou decadência? Projeto de Iniciação Científica PIBIC/CNPq UEM. (mimeografado).

Abeche, R. P. C.; Ferreira Junior, A. G. (2005) "Ficando" sem ficar: a astúcia da Indústria Cultural. Revista Psico, v. 41. n. 3. 2010.

Adorno, T. W. (1971 / 2006) Educação e Emancipação. 4 ed. Tradução: Wolfgang Leo Maar. Rio de Janeiro: Paz e Terra.

Adorno, T. W. (1947) Indústria Cultural: o esclarecimento como mistificação das massas. Em: Dialética do esclarecimento - fragmentos filosóficos. Trad. G. A. Almeida. Rio de Janeiro: [s.n.], 2006, 57-79.

Adorno, T. W. Indústria Cultural. (1978) Em: Cohn, G. (org). Comunicação e Indústria cultural: leituras de análise dos meios de comunicação na sociedade contemporânea e das manifestações da opinião pública, propaganda e cultura de massa nessa sociedade. São Paulo: Nacional, p. 287-295.

Caniato, A. M. P.; Martins, D. e Teixeira, P. (2008) Modelos identificatórios e padronização das subjetividades: um olhar atento sobre os personagens da telenovela malhação. Programa de 
Iniciação Científica/PIC.

Universidade Estadual de Maringá:

Maringá.

Dufour, D. R. (2001) Os extravios do indivíduo-sujeito. Tradução de Selvino José Assmann. Le Monde Diplomatique. Paris, fev. 2001.

Dufour, D. R. A arte de reduzir as mentes. Le Monde Diplomatique. [S.1.], out. 2003. Disponível em: $<$ http://diplo.uol.com.br/imprima763 > Acesso em: 2 mar. 2008.

Enriquez, E. O homem do século XXI: sujeito autônomo ou indivíduo descartável. RAE eletrônica. Tradução por Maria Ester de Freitas. v. 5, n. 1, art. 10, jan/jun 2006. Disponível em: <http://www.rae.com.br/eletronica> Acesso em: 3 jun. 2006.

Fabiano, L. H. (2001) Ética e sociedade: razão teórica versus razão técnica. Maringá: [s.n.], out.

Freud, S. (1921) Psicología de las masas. 6 ed. Tradução: Luis LópezBallesteros y de Torres. Madrid: Alianza Editorial, 2005.

Freud, S. (1930). O Mal-estar na civilização. v. XXI. Imago: Rio de Janeiro, 2006.

González Rey, F. (2005) Pesquisa qualitativa e subjetividade: os processos da construção da informação. São Paulo: Pioneira Thompson Learning.

Groeninga, G. C. (2003) Família: um caleidoscópio de relações. In: Groeninga, G. C. \& Pereira, R. C. (coord.). Direito de família $e$ psicanálise: Rumo a uma nova epistemologia. Rio de Janeiro: Imago, p. 125-142.

Kehl, M. R. (2003) Em defesa da família tentacular. In: Groeninga, G. C. \& Pereira, R. C. (coord.) Direito de família e psicanálise: rumo a uma nova epistemologia. Rio de Janeiro: imago, p. 163-176.

Lakatos, E. M. e Marconi, M. A. (2006) Metodologia do trabalho científico: Procedimentos básicos, pesquisa bibliográfica, projeto e relatório, publicações e trabalhos científicos. São Paulo: Atlas.

Laplanche, J.; e Pontalis, J.-B. Diccionario de psicoanalisis. Buenos Aires: Paidós Lucchesi, I. Mídia $e$ a sedução sem encantamento. v. 1. Rio de Janeiro: Observatório da Imprensa, 2002.

Martins, R. M. (2009) Desamparo $e$ Subjetividade: a figura do pai na contemporaneidade. 176 fls. Dissertação (Mestrado em psicologia) - Universidade Estadual de Maringá. Orientador: prof ${ }^{a}$ dra. 
Angela Maria Pires Caniato. Maringá.

Salazar, M. C. A. (2002) Resignificando Valores na Família: Em Busca de Uma Nova Ética. São Paulo. Disponível em:

<http://www.revistapsicologia.com.b r/revista44D/index.htm> Acesso em: 02 jun. 2008.

Tenzer, N. (1991) La sociedad despolitizada: ensayo sobre los fundamentos de la politica. Buenos Aires: Paidós, p. 165-181.

\section{Regina Perez Christoffolli Abeche:}

Graduada em Psicologia pela Universidade Estadual de Maringá e Doutorado em Ciências da Religião pela Universidade Metodista de São Paulo. Professora supervisora da área clínica e professora do Programa de Pós-graduação na área de concentração: Epistemologia e Práxis em Psicologia, do Departamento de Psicologia, da Universidade Estadual de Maringá.

E-mail: abeche@wnet.com.br

Rodrigo Daniel Trevizan: graduado em Psicologia pela Universidade Estadual de Maringá e integrante do projeto de pesquisa e intervenção "Phenix: a ousadia do renascimento do indivíduo sujeito. fase III" vinculado ao Departamento de Psicologia desta mesma Universidade.
Anne Caroline Alves Peres: Aluna do Curso de Psicologia da Universidade Estadual de Maringá. 